\title{
Effect of pentoxifylline on proteinuria, markers of tubular injury and oxidative stress in non-diabetic patients with chronic kidney disease - placebo controlled, randomized, cross-over study
}

\author{
Marcin Renke ${ }^{1 凶}$, Leszek Tylicki ${ }^{1}$, Przemysław Rutkowski ${ }^{1}$, Narcyz Knap ${ }^{2}$, Marcin Ziętkiewicz ${ }^{3}$, \\ Alexander Neuwelt ${ }^{4}$, Ewa Aleksandrowicz ${ }^{5}$, Wiesława Łysiak-Szydłowska ${ }^{5}$, Michał Woźniak ${ }^{2}$ \\ and Bolesław Rutkowski ${ }^{1}$ \\ 'Department of Nephrology, Transplantology and Internal Medicine, ${ }^{2}$ Department of Medical Chemistry, ${ }^{3}$ Department of Internal Medicine, \\ Connective Tissue Diseases and Geriatrics, Medical University of Gdańsk, Gdańsk, Poland; ‘Blood Brain Barrier and Neuro-Oncology Program, \\ Oregon Health \& Science University, Portland, Oregon, USA; 5 Department of Clinical Nutrition and Laboratory Diagnostics. Medical University \\ of Gdańsk, Gdańsk, Poland
}

Background: Inhibition of the renin-angiotensin-aldosterone system (RAAS) with angiotensin converting enzyme inhibitors (ACEI) and/or angiotensin II subtype 1 receptor antagonists (ARB) is a common strategy used in the management of patients with chronic kidney disease (CKD). However, there is no universal therapy that can stop progression of CKD. Pentoxifylline (PTE) is a nonspecific phosphodiesterase inhibitor with anti-inflammatory properties. It has been reported to have promising effects in CKD treatment. Methods: In a placebo-controlled, randomized, cross-over study we evaluated the influence of PTE (1200 mg/day) added to RAAS blockade on proteinuria, surrogate markers of tubular injury and oxidative stress-dependent products in 22 non-diabetic patients with proteinuria $(0.4-4.3 \mathrm{~g}$ per $24 \mathrm{~h})$ with normal or declined kidney function [eGFR 37-178 mL/min]. In an eight-week run-in period, therapy using ACEI and/ or ARB was adjusted to achieve a blood pressure below $130 / 80 \mathrm{~mm} \mathrm{Hg}$. Next, patients were randomly assigned to one of two treatment sequences: PTE/washout/placebo or placebo/washout/PTE. Clinical evaluation and laboratory tests were performed at the randomization point and after each period of the study. Results: The PTE therapy reduced proteinuria (by $26 \%$ ) as compared to placebo. There were no differences in $a_{1}$-microglobulin, urine excretion of $N$-acetyl- $\beta$-D-glucosaminidase (NAG), hsCRP, the urinary excretion of $15-\mathrm{F}_{2 \mathrm{t}}$-isoprostane, blood pressure (BP), eGFR and serum creatinine between the PTE and placebo groups. Conclusion: Pentoxifylline may decrease proteinuria in non-diabetic patients with CKD.

Keywords: pentoxifylline, oxidative stress, kidney, chronic kidney disease, proteinuria, tubular injury

Received: 04 January, 2010; revised: 11 March, 20201; accepted: 19 March, 2010; available on-line: 22 March, 2010

\section{INTRODUCTION}

The incidence and prevalence of chronic kidney disease (CKD) is increasing worldwide. Pharmacological inhibition of the renin-angiotensin-aldosterone system (RAAS) constitutes a cornerstone strategy in the management of patients with chronic nephropathies with proteinuria (Tylicki et al., 2005). Angiotensin converting enzyme inhibitors (ACEI) and angiotensin II subtype 1 receptor antagonists (ARB) have been shown to decrease proteinuria, reduce local renal inflammatory processes and slow down the progression of renal insufficiency (Renke et al., 2004; Renke et al., 2005; Rutkowski et al., 2004; Tylicki et al., 2007a; 2007b). Despite recent progress, there is still no optimal therapy that stops progression of CKD. Therefore, it is necessary to search for alternative therapeutic strategies which can further improve renal outcome.

Considering the prognostic impact of proteinuria reduction on long-term renal outcome, in the present study we evaluated the effects of pentoxifylline (PTE) addition to background nephroprotective therapy consisting of ACEI and/or ARB. PTE, a methyl-xanthine derivative, is a non-selective phosphodiesterase inhibitor with anti-inflammatory and immunomodulatory effects. PTE is also widely used to treat peripheral vascular disorders because of its potent hemorrheological properties (Frampton \& Brogden, 1995). Moreover, P'TE potently inhibits cell proliferation and extracellular matrix accumulation, factors that play important roles in CKD progression. The PTE's benefit when administered in conjunction with RAAS blockade in patients with CKD is not clear. Our study evaluated the effects of this treatment on proteinuria, inflammation, oxidative stress, renal function and surrogate markers of tubular injury.

\section{MATERIAL AND METHODS}

Individuals. Patients were selected from the cohort that attended our renal outpatient department. The inclusion criteria were as follows: age 18-65 years, chronic non-diabetic proteinuric nephropathy without dyslipidemia, normal or slightly impaired stable renal function expressed as estimated glomerular filtration rate (eGFR)

$\triangle$ e-mail: mrenke@gumed.edu.pl

Abbreviations: ACEl, angiotensin converting enzyme inhibitors; ARB, angiotensin II subtype 1 receptor antagonists; BP, blood pres sure; CKD, chronic kidney disease; CVD, cardiovascular diseases; DPE, 24-h urinary protein excretion; eGFR, estiamted glomerular filtration rate; PTE, pentoxifylline; RAAS, renin-angiotensin-aldosterone system. 
Table 1. Patient characteristics at baseline

\begin{tabular}{lc}
\hline Parameter & \\
\hline Gender: female/male (n) & $7 / 15$ \\
Mean age years ( \pm S.E.M.) & $38.6 \pm 10.3$ \\
Mean systolic blood pressure & $123.8 \pm 12.6$ \\
mm Hg $( \pm$ S.E.M.) & \\
Mean diastolic blood pressure mm Hg & $75.3(70.6-81.0)$ \\
Urinary protein excretion g/24h & $1.2(0.4-4.3)$ \\
Serum creatinine mg/dL & $1.0(0.9-1.3)$ \\
eGFR mL/min ( \pm S.E.M.) & $121.8 \pm 50.2$ \\
hsCRP mg/L & $2.36(0.29-10.4)$ \\
BMI kg/m² & $27.7(19.3-36.1)$ \\
Histopathological diagnosis: $(n)$ & 14 \\
Mesangial glomerulonephritis & 4 \\
Mesangiocapillary glomerulonephritis & 1 \\
Membranous glomerulonephritis & 2 \\
Focal segmental glomerulosclerosis & 2 \\
(FSGS) & \\
IgA nephropathy & \\
Unknown non-diabetic proteinuric & \\
chronic kidney diseases & \\
Background hypotensive therapy: (n) & \\
ACEl and ARB & \\
ACEl & \\
ARB & \\
\hline & \\
\hline
\end{tabular}

above $30 \mathrm{~mL} / \mathrm{min}$, stable proteinuria above $300 \mathrm{mg} /$ $24 \mathrm{~h}$, and no steroids or other immunosuppressive treatment for a minimum of six months before the study. Stable renal function and proteinuria were defined as a variability of serum creatinine and proteinuria less than $20 \%$ during 6 months before the start of the study. Exclusion criteria were as follows: fertile women who were not taking oral contraceptives, pregnant or lactating women, and a history of adverse reactions to PTE.

General protocol. The study was a prospective, placebo-controlled, randomized, two-period cross-over trial in which the renal effects of adding PTE to a background nephroprotective therapy with ACEI and/or ARB were evaluated. Subjects entered an eight-week run-in period during which background nephroprotective therapy using pharmacological blockade of RAAS was adjusted to keep target blood pressure (BP) below 130/80 mm Hg (Table 1). At the end of the run-in period, patients were randomly assigned to one of two treatment sequences: 8-week PTE (1200 mg/day)/8-week washout — background therapy/8-week placebo (sequence 1) or 8 -week placebo/8-week washout — background therapy/8-week PTE (1200 mg/day) (sequence 2) (Fig. 1). The allocation was performed according to a computer-generated randomization list by a person that was independent of the research team. The patients received $1200 \mathrm{mg}$ of PTE, in tablet form (Polfilin 400, Polpharma), once a day. The dosages of ACEI, ARB and diuretics, once established in the run-in period, were left unchanged throughout the study. At the randomization point, and after the end of each treatment period, office through BP, serum creatinine, potassium, hsCRP, proteinuria (measured as 24-h

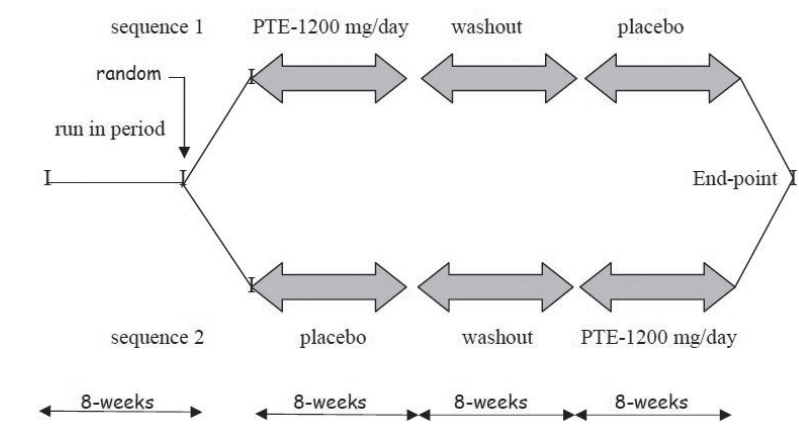

Figure 1. Study scheme

urinary protein excretion (DPE)), sodium excretion $(\mathrm{Na}$ ex), and urea excretion were measured. Further, surrogate markers of tubular injury were analyzed, namely urine excretion of $N$-acetyl- $\beta$-D-glucosaminidase (NAG), $\alpha-{ }_{1}$ microglobulin $(\alpha 1 \mathrm{~m})$ and $15-\mathrm{F}_{2 \mathrm{t}}$-isoprostane. $15-\mathrm{F}_{2 \mathrm{t}}{ }^{-}$ isoprostane is accepted as a reliable and sensitive marker of oxidative stress in human pathologies (Fam \& Morrow, 2003). The study was approved by the local ethical committee and the investigated patients all gave informed consent.

Procedures and laboratory analyses. The office through BP was measured with a Speidel+Keller sphyngomanometer in a sitting position after $10 \mathrm{~min}$ of rest and expressed as a mean value of two consecutive measurements taken $2 \mathrm{~min}$ apart. DPE, Na ex and urea excretion were evaluated on the basis of 24-h urine collection. All patients were equipped with a graded container and were informed how to collect 24-h urine. They collected two 24-h urines - of those the mean value of DPE was calculated for data evaluation. Patients were asked not to perform heavy physical activity on the urine collection days and were recommended not to change their usual daily protein and sodium intake during the study period. The excretion of urea was used to calculate the protein intake according to the Maroni equation: protein intake normalized to weight (g/ $\mathrm{kg}$ per day $)=6.25 \times($ [urea-N-excretion urine $24 \mathrm{~h}(\mathrm{~g} /$ day) $]+[0.0031 \times$ body weight $(\mathrm{kg})]) /$ body weight $(\mathrm{kg})$ (Maroni et al., 1985). eGFR was calculated according to the Cockcroft-Gault formula (Cockcroft \& Gault, 1976). NAG and $\alpha 1 \mathrm{~m}$ were analyzed in the second morning spot urine sample. NAG was determined by the spectrophotometric method according to Maruhn (1976). Incubation medium had a final volume of 0.4 $\mathrm{mL}$, containing $5 \mathrm{nmol} / \mathrm{L}$-nitrophenyl-2-acetamido$\beta$-D-glucopyranoside as a substrate in $50 \mathrm{mmol} / \mathrm{L}$ citrate buffer ( $\mathrm{pH}$ 4.14). The reaction was started by the addition of $0.2 \mathrm{~mL}$ of undialysed urine, carried out for $15 \mathrm{~min}$ at $37^{\circ} \mathrm{C}$, and then terminated with $1 \mathrm{~mL}$ of glycine buffer, $\mathrm{pH}$ 10.5. Absorbance was measured at $405 \mathrm{~nm}$ against a sample terminated at time zero. The calculation of the NAG level was made from the molar absorption coefficient of the product of the reaction, $p$-nitrophenol, which is $18.5 \mathrm{~cm}^{2} / \mu \mathrm{mol}$. From preliminary experiments it was clear that the dialysis did not affect NAG levels in the urine. Immunoturbidimetric test (Tina-quant $\alpha_{1}$-microglobulin, Roche, Basel, Switzerland) was used for the quantification of $\alpha 1 \mathrm{~m}$ in urine. The detection limit of the method was $2 \mathrm{mg} / \mathrm{L}$. Urinary $\mathrm{NAG}$, and $\alpha 1 \mathrm{~m}$ were reported per mass of urine creatinine to correct for the variation in urine concentration. High sensitivity C-reac- 
Table 2. Changes of parameters after PTE and placebo

\begin{tabular}{lccc}
\hline & PTE - Baseline $(\Delta)$ & Placebo - Baseline $(\Delta)$ & $P$ \\
\hline Proteinuria (DPE) g/24 h & $-0.41 \pm 0.48$ & $0.01 \pm 0.62$ & 0.11 \\
a1m excretion mg/g creatinine & $0.61(-8.4-9.6)$ & $0.41(-5.7-6.5)$ & 0.96 \\
NAG excretion IU/g creatinine & $1.0 \pm 1.96$ & $1.16 \pm 4.9$ & 0.91 \\
hsCRP mg/L & $-1.66 \pm 1.77$ & $-0.89 \pm 4.69$ & 0.63 \\
Urine excretion of iPF2a ng/mg creatinine & $0.08(-0.01-0.18)$ & $-0.04(-0.12-0.03)$ & 0.8 \\
\hline
\end{tabular}

tive protein (hsCRP) was measured with a commercial ELISA kit (DRG, EIA-3954) and reported as $\mathrm{mg} / \mathrm{L}$. A commercial ELISA kit (Cayman Chemical Co.) was then used to measure the urinary excretion of $15-\mathrm{F}_{2 \mathrm{t}}{ }^{-}$ isoprostane in the treated patients. Potassium, sodium, urea, protein and creatinine levels were measured in fresh blood samples drawn after fasting overnight for at least $12 \mathrm{~h}$. These parameters were measured using standard laboratory techniques. Body mass index (BMI) was calculated as weight (kilograms) divided by height (meters) squared. Adverse effects were recorded at each visit in response to questionnaires or as observed by the investigators.

Statistics. The primary end point of this study was a change in DPE in measurements available for each patient after treatment with PTE and placebo. The sample size of 16 patients adequately allowed a power of $80 \%$ to detect a difference in variables equal to within one standard deviation, that is a standardized effect size of 1.0 at a significance level of 0.05 (two-tailed). Secondary end points included urine NAG, $\alpha 1 \mathrm{~m}$, and $15-\mathrm{F}_{2 \mathrm{t}}$-isoprostane excretions. Normality and homogeneity of the variances were verified by means of the Shapiro-Wilk test and Levene test, respectively. Because of their skewed distribution, diastolic BP, DPE, NAG excretion, $15-\mathrm{F}_{2 \mathrm{t}}$-isoprostane, hsCRP, serum creatinine and daily protein intake were logarithmically transformed before statistical analysis, and expressed as geometric means and 95\% confidence intervals. Other results are presented as means \pm S.E.M. Differences in the variables' changes between treatment with PTE and placebo were assessed using Student's t-test (Table 2). The differences in the variables measured more than twice (Table 3) were assessed using ANOVA. P less than 0.05 (2-tailed) was considered statistically significant. Data were evaluated using Statistica (version 7.1; StatSoft Inc, Tulsa, OK) software package.

\section{RESULTS}

Of the 22 patients who entered the study, $14(64 \%)$ completed the protocol. Five of the patients dropped out because of the withdrawal of informed consent due to a side effect of therapy (gastrointestinal symptoms - $23 \%$ ). The other patients resigned from participation in the study for personal reasons. Clinical characteristics of the patients are listed in Table 1.

\section{4-h urinary protein excretion (DPE)}

The PTE therapy reduced proteinuria (by 26\%) as compared to placebo, but the result was not significant $(P=0.11)$ (Table 2). The exact change of DPE in single patients before and after PTE is shown separately (Fig. 2)

\section{Urinary NAG and a1m excretion}

There were no significant changes in urinary NAG $(P=0.91)$ and $\alpha 1 \mathrm{~m}$ excretion level $(P=0.96)$ using PTE as compared to placebo (Table 2).

\section{$15-\mathrm{F}_{2 \mathrm{t}}$-isoprostane excretions and hsCRP}

There were no significant changes in $15-\mathrm{F}_{2 \mathrm{t}}$-isoprostane excretions and hsCRP during the study (Table 2).

\section{Blood pressure, renal function, sodium and protein intake}

The control of BP was adequate in all study periods; all patients reached the target office trough BP below 130/80 $\mathrm{mm} \mathrm{Hg}$. There were no differences in the office through systolic and diastolic BP between the treatment periods. Renal function assessed by means of serum creatinine and eGFR remained stable during the study periods. There were no differences in sodium and protein intake between treatment periods (Table 3).

\section{Safety}

Interestingly, the PTE therapy was not well tolerated in this study. Adverse effects were reported in five patients $(22.7 \%)$ who suffered from gastrointestinal symptoms - nausea, dyspepsia and diarrhea.

Table 3. Changes of parameters during study

\begin{tabular}{lllll}
\hline Parameter & Randomization point & After PTE & After Placebo & $P$ \\
\hline Na urinary excretion mmol/24 h & $295 \pm 30.2$ & $247 \pm 34.5$ & $268 \pm 35.5$ & 0.64 \\
Daily protein intake g/24 h & $1.1 \pm 0.3$ & $1.1 \pm 0.3$ & $1.0 \pm 0.3$ & 0.45 \\
Serum creatinine mg/dL & $1.0(0.9-1.3)$ & $1.1(0.9-1.4)$ & $1.1(0.9-1.5)$ & 0.86 \\
Systolic BP mm Hg & $123.8 \pm 12.6$ & $122.9 \pm 11.2$ & $123.8 \pm 10$ & 0.55 \\
Diastolic BP mm Hg & $75.3(70.6-81.0)$ & $74.3(70.2-79.0)$ & $77.6(73.8-82.1)$ & 0.64 \\
\hline
\end{tabular}




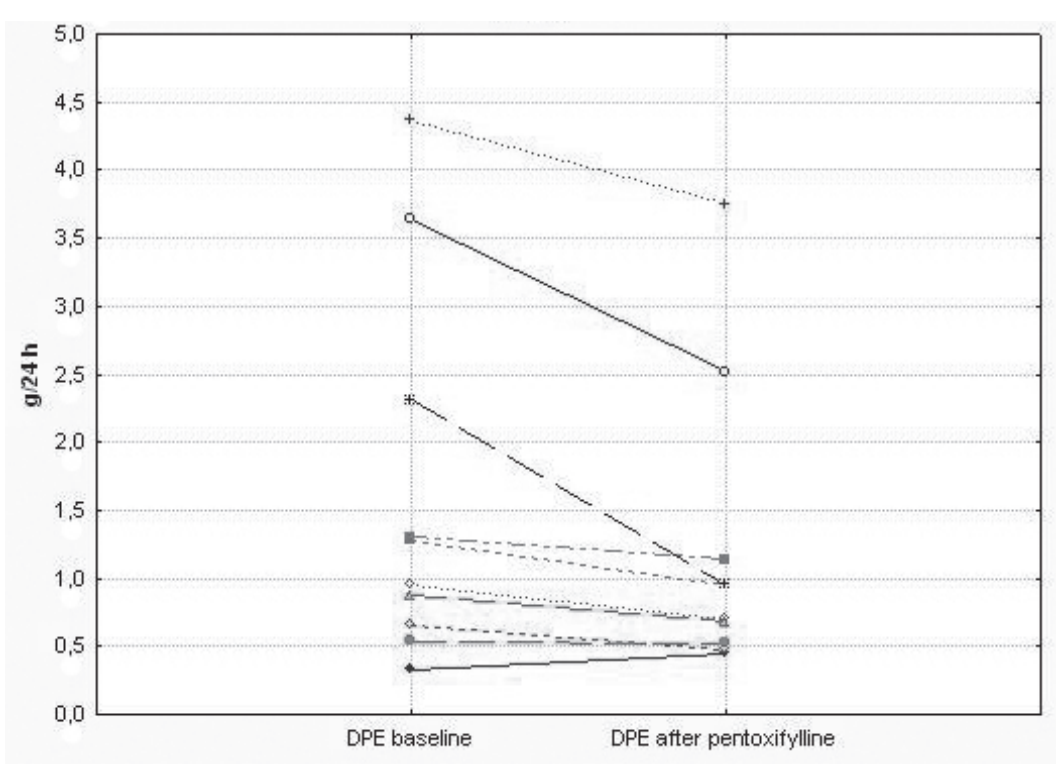

Figure 2. Daily protein excretion (DPE) before and after the therapy with pentoxifylline.

\section{DISCUSSION}

To the best of our knowledge the present study was the first to evaluate tubulointerstitial effects of pentoxifylline in proteinuric non-diabetic CKD patients. PTE has potential value as an antiproliferative and antifibrogenic agent, an effect documented in animal research (Chen et al., 1999a; 1999b; Lin et al., 2005) and in patients with diabetic kidney disease (Navarro et al., 2003). Considering that tubular epithelial cell injury may initiate the fibrotic process in kidneys and that the extent of tubulointerstitial damage is a crucial predictor of renal outcome, tubular cells have become a site of particular interest. To evaluate the tubulointerstitial effects of the described interventions, the tubular involvement markers NAG and $\alpha 1 \mathrm{~m}$ were analyzed (Bazzi et al., 2002). An increased excretion of NAG is thought to be a specific marker of tubular injury in many renal pathologies including non-diabetic CKD (Bazzi et al., 2002). Increased urinary excretion of $\alpha 1 \mathrm{~m}$, a low-molecular weight protein physiologically filtered and reabsorbed by tubular cells, may indicate a reduced capacity of reabsorption by tubular cells, and thus can act as a marker of established tubular damage, with greater urinary concentrations suggesting greater severity of damage (Holdt-Lehmann et al., 2000). Our results show that treatment with PTE had no influence on these markers of tubular injury.

The effects of PTE $(1200 \mathrm{mg} /$ day $)$ on proteinuria were also analyzed. Proteinuria is considered a marker of long-term renal outcome. In the present study, the administration of PTE decreased the proteinuria levels in non-diabetic CKD patients, but this was not significant $(P=0.11)$. Only a few randomized controlled trials directly addressing the effect of PTE on renal function and proteinuria have been reported. Most of those studies were of small size or short duration, used a variety of doses, and many did not include a placebo arm. Some of these studies suggest that PTE reduces proteinuria (Ducloux et al., 2001; Galindo-Rodriguez et al., 2003; Lin et al., 2008) and the rate of GFR decline (Perkins et al., 2009). These positive effects were summarized in published meta-analyses (McCormick et al., 2008) and review articles (Lin et al., 2004; Lin et al., 2005; Renke et al., 2008; Vilayur \& Harris, 2009). The pleiotropic effects of PTE have important clinical implications, as it displays anti-tumor necrosis factor alpha (TNF- $\alpha$ ) (Mandell, 1995) and anti-interferon gamma (IFN- $\gamma$ ) (Benbernou et al., 1995; Bienvenu et al., 1995) action, as well as antioxidant (Freitas \& Filipe, 1995) and antiapoptotic effects (Belloc et al., 1995). Patients with CKD are at increased risk for cardiovascular disease (CVD), and recent reviews suggest that inflammation and oxidative stress could be the primary mediators of CVD in CKD patients (Arici \& Walls, 2001). Moreover, inflammation plays a central role in the progression of CKD (Tonelli et al., 2005; Zoja et al., 2006). In our study we used hsCRP, a protein found in the blood, as a marker of inflammatory process. Interestingly, patients with elevated basal levels of CRP are at an increased risk of diabetes, hypertension and cardiovascular disease (Pradhan et al., 2001; Dehghan et al., 2007). In our study this parameter had a tendency to decrease with PTE treatment $(70 \%)$, but the result was not statistically significant $(P=0.63)$. The facts that most of the patients had serum hsCRP levels within the normal range at the beginning of the study and the small number of participants are probably the main reasons why our results differ from those of other studies. The urinary excretion of $15-\mathrm{F}_{2 t}$-isoprostane, a reliable and sensitive marker of oxidative stress, was also measured. Urinary excretion of $15-\mathrm{F}_{2 \mathrm{t}}$-isoprostane was not found to change with treatment $(P=0.8)$. Interestingly, the PTE therapy was not well tolerated in this study, a finding in contrast to the perception that PTE has few side effects in CKD patients (Ward \& Clissold, 1987; McCormick et al., 2008). Adverse effects, namely gastrointestinal symptoms, were reported in 5 patients $(23 \%)$ during the study period. This finding is perhaps attributable to accumulation of PTE metabolites, a known mechanism of toxicity in patients with chronic renal failure (Paap et al., 1996). In the present study, the PTE doses were unchanged in patients with moderate renal dysfunction (Navarro et al., 2003).

A potential limitation of the study is the relatively small sample size, which was unsufficiently powered to detect a significant difference equal to the S.D. value between treatment periods. Further, 24-h urine collections used to assess proteinuria may be associated with significant collection errors, largely because of improper timing and missed samples, leading to overcollection and undercollection.

In conclusion, the study results suggest that treatment with PTE (1200 mg/day) for 8 weeks in nondialysed patients with CKD induced the reduction of DPE (by $26 \%$ ), without affecting markers of tubular injury and 
oxidative stress. However, the potential nephroprotective properties of PTE need to be addressed further in future controlled long term studies.

\section{Acknowledgements}

The study was supported by grant from the State Committee for Scientific Research via the Medical University of Gdańsk (ST-4).

The authors thank Polpharma for providing drugs. The drug providers and sponsors had no involvement in the study design, patient recruitment, analysis, interpretation of data, writing of the report, or the decision to submit the report for publication.

\section{REFERENCES}

Arici M, Walls J (2001) End-stage renal disease, atherosclerosis, and cardiovascular mortality: is C-reactive protein the missing link? Kidney Int 59: 407-414.

Bazzi C, Petrini C, Rizza V, Arrigo G, Napodano P, Paparella M, D'Amico G (2002) Urinary $N$-acetyl- $\beta$-glucosaminidase excretion is a marker of tubular cell dysfunction and a predictor of outcome in primary glomerulonephritis. Nephrol Dial Transplant 17: 1890-1896.

Belloc F, Jaloustre C, Dumain P, Lacombe F, Lenoble M, Boisseau MR (1995) Effect of pentoxifylline on apoptosis of cultured cells. J Cardiovasc Pharmacol 25 (Suppl 2): S71-S74.

Benbernou N, Esnault S, Potron G, Guenounou M (1995) Regulatory effects of pentoxifylline on T-helper cell-derived cytokine production in human blood cells. J Cardiovasc Pharmacol 25 (Suppl 2): S75S79.

Bienvenu J, Doche C, Gutowski MC, Lenoble M, Lepape A, Perdrix JP (1995) Production of proinflammatory cytokines and cytokines involved in the TH1/TH2 balance is modulated by pentoxifylline. $J$ Cardiovasc Pharmacol 25 (Suppl 2): S80-S84.

Chen YM, Chien CT, Hu-Tsai MI, Wu KD, Tsai CC, Wu MS, Tsai TJ (1999a) Pentoxifylline attenuates experimental mesangial proliferative glomerulonephritis. Kidney Int 56: 932-943.

Chen YM, Wu KD, Tsai TJ, Hsieh BS (1999b) Pentoxifylline inhibits PDGF-induced proliferation of and TGF- $\beta$-stimulated collagen synthesis by vascular smooth muscle cells. J Mol Cell Cardiol 31: $773-783$.

Cockcroft DW, Gault MH (1976) Prediction of creatinine clearance from serum creatinine. Nephron 16: 31-41.

Dehghan A, Kardys I, de Maat MP, Uitterlinden AG, Sijbrands EJ, Bootsma AH, Stijnen T, Hofman A, Schram MT, Witteman JC (2007) Genetic variation, C-reactive protein levels, and incidence of diabetes. Diabetes 56: 872-878.

Ducloux D, Bresson-Vautrin C, Chalopin J (2001) Use of pentoxifylline in membranous nephropathy. Lancet 357: 1672-1673.

Fam SS, Morrow JD (2003) The isoprostanes: unique products of arachidonic acid oxidation — a review. Curr Med Chem 10: 1723-1740.

Frampton JE, Brogden RN (1995) Pentoxifylline (oxpentifylline) A review of its therapeutic efficacy in the management of peripheral vascular and cerebrovascular disorders. Drugs Aging 7: 480-503.

Freitas JP, Filipe PM (1995) Pentoxifylline. A hydroxyl radical scavenger. Biol Trace Elem Res 47: 307-311.

Galindo-Rodriguez G, Bustamante R, Esquivel-Nava G, Salazar-Exaire D, Vela-Ojeda J, Vadillo-Buenfil M, Avina-Zubieta JA (2003) Pentoxifylline in the treatment of refractory nephrotic syndrome secondary to lupus nephritis. J Rheumatol 30: 2382-2384.

Holdt-Lehmann B, Lehmann A, Korten G, Nagel H, Nizze H, Schuff-Werner P (2000) Diagnostic value of urinary alanine aminopeptidase and $N$-acetyl- $\beta$-D-glucosaminidase in comparison to $\alpha 1$-microglobulin as a marker in evaluating tubular dysfunction in glomerulonephritis patients. Clin Chim Acta 297: 93-102.

Lin SL, Chen YM, Chiang WC, Tsai TJ, Chen WY (2004) Pentoxifylline: a potential therapy for chronic kidney disease. Nephrology (Carlton) 9: 198-204.
Lin SL, Chen RH, Chen YM, Chiang WC, Lai CF, Wu KD, Tsai TJ (2005) Pentoxifylline attenuates tubulointerstitial fibrosis by blocking Smad3/4-activated transcription and profibrogenic effects of connective tissue growth factor. I Am Soc Nephrol 16: 2702-2713.

Lin SL, Chiang WC, Chen YM, Lai CF, Tsai TJ, Hsieh BS (2005) The renoprotective potential of pentoxifylline in chronic kidney disease. J Chin Med Assoc 68: 99-105.

Lin SL, Chen YM, Chiang WC, Wu KD, Tsai TJ (2008) Effect of pentoxifylline in addition to losartan on proteinuria and GFR in CKD: a 12-month randomized trial. Am J Kidney Dis 52: 464-474.

Mandell GL (1995) Cytokines, phagocytes, and pentoxifylline. I Cardiovasc Pharmacol 25 (Suppl 2): S20-S22.

Maroni BJ, Steinman TI, Mitch WE (1985) A method for estimating nitrogen intake of patients with chronic renal failure. Kidney Int 27: 58-65.

Maruhn D (1976) Rapid colorimetric assay of $\beta$-galactosidase and $N$-acetyl- $\beta$-glucosaminidase in human urine. Clin Chim Acta 73: 453-461.

McCormick BB, Sydor A, Akbari A, Fergusson D, Doucette S, Knoll $G$ (2008) The effect of pentoxifylline on proteinuria in diabetic kidney disease: a meta-analysis. Am J Kidney Dis 52: 454-463.

Navarro JF, Mora C, Muros M, Maca M, Garca J (2003) Effects of pentoxifylline administration on urinary $N$-acetyl- $\beta$-glucosaminidase excretion in type 2 diabetic patients: a short-term, prospective, randomized study. Am J Kidney Dis 42: 264-270.

Paap CM, Simpson KS, Horton MW, Schaefer KL, Lassman HB, Sack MR (1996) Multiple-dose pharmacokinetics of pentoxifylline and its metabolites during renal insufficiency. Ann Pharmacother 30: 724-729.

Perkins RM, Aboudara MC, Uy AL, Olson SW, Cushner HM, Yuan CM (2009) Effect of pentoxifylline on GFR decline in CKD: a pilot, double-blind, randomized, placebo-controlled trial. Am J Kidney Dis 53: 606-616.

Pradhan AD, Manson JE, Rifai N, Buring JE, Ridker PM (2001) C-reactive protein, interleukin 6 , and risk of developing type 2 diabetes mellitus. IAMA 286: 327-334.

Renke M, Rutkowski P, Tylicki L, Zietkiewicz M, Larczynski W, Rutkowski B (2008) Pentoxifylline old drug or new hope for nephrology? Pryegl Lek 65: 358-361 (in Polish).

Renke M, Tylicki L, Rutkowski P, Rutkowski B (2004) Low-dose angiotensin II receptor antagonists and angiotensin II-converting enzyme inhibitors alone or in combination for treatment of primary glomerulonephritis. Scand J Urol Nephrol 38: 427-433.

Renke M, Tylicki L, Rutkowski P, Wojnarowski K, Lysiak-Szydlowska W, Rutkowski B (2005) Low-dose dual blockade of the renin-angiotensin system improves tubular status in non-diabetic proteinuric patients. Scand J Urol Nephrol 39: 511-517.

Rutkowski P, Tylicki L, Renke M, Korejwo G, Zdrojewski Z, Rutkowski B (2004) Low-dose dual blockade of the renin-angiotensin system in patients with primary glomerulonephritis. Am J Kidney Dis 43: 260-268.

Tonelli M, Sacks F, Pfeffer M, Jhangri GS, Curhan G (2005) Biomarkers of inflammation and progression of chronic kidney disease. Kidney Int 68: 237-245.

Tylicki L, Larczynski W, Rutkowski B (2005) Renal protective effects of the renin-angiotensin-aldosterone system blockade: from evidence-based approach to perspectives. Kidney Blood Press Res 28: 230-242.

Tylicki L, Biedunkiewicz B, Chamienia A, Wojnarowski K, Zdrojewski Z, Aleksandrowicz E, Lysiak-Szydlowska W, Rutkowski B (2007a) Renal allograft protection with angiotensin II type 1 receptor antagonists. Am J Transplant 7: 243-248.

Tylicki L, Rutkowski P, Renke M, Rutkowski B (2007b) Addition of aldosterone receptor blocker to dual renin-angiotensin-aldosterone blockade leads to limitation of tubulointerstitial injury of kidney. Kidney Int 72: 1164-1165.

Vilayur E, Harris DC (2009) Emerging therapies for chronic kidney disease: what is their role? Nat Rev Nephrol 5: 375-383.

Ward A, Clissold SP (1987) Pentoxifylline. A review of its pharmacodynamic and pharmacokinetic properties, and its therapeutic efficacy. Drugs 34: 50-97.

Zoja C, Abbate M, Remuzzi G (2006) Progression of chronic kidney disease: insights from animal models. Curr Opin Nephrol Hypertens 15: 250-257. 